\title{
Thermal Optical Analysis of Cholesteryl Methacrylate and Methyl Methacrylate Copolymers
}

\author{
Kikuo SHōJI, Yukio NAKAJIMA, Eiichi UEDA, \\ and Masatami TAKEDA \\ Department of Chemistry, Faculty of Science, Science University of Tokyo, \\ Kagurazaka, Shinjuku-ku, Tokyo 162, Japan
}

(Received January 17, 1985)

\begin{abstract}
As side chain types of liquid crystalline polymers, cholesteryl methacrylate (ChMA) homopolymer and ChMA-methyl methacrylate copolymer ( $p$-ChMA-MMA) were synthesized. The copolymer was a type of direct coupling side chain, a mesogenic side group directly bonded to the main chain without a flexible spacer. Since the observation of the transition temperature with polarized microscopy was not effective in this case, the mesomorphic behavior of the copolymers was studied by thermal optical analysis (TOA). Moreover, the effect of the casting method on the mesomorphic behavior was studied. It became clear that the isotropic temperature of the copolymer with a large fraction of ChMA was particularly effected by the casting method. The correlation between the thermotropic nature and stereoregularity of $p$-ChMA-MMA was also studied. The copolymers containing more than $72 \mathrm{~mol} \%$ of ChMA were syndiotactic rich and exhibited a remarkable thermotropic mesophase.

KEY WORDS Poly(cholesteryl methacrylate-methyl methacrylate) / Optical Anisotropy / Mesophase / Thermal Optical Analysis / Stereoregularity /
\end{abstract}

In recent years, it has been reported that polymers with a cholesterol moiety attached to back-bones through a long flexible molecular spacer exhibit enantiotropic liquid crystalline behavior. ${ }^{1-5}$ However, the mesomorphic order in polymers with side groups containing the cholesterol moiety attached directly to the main chain has received little attention. ${ }^{6-10}$ In this study, attention has been directly focused on the phase transitions of cholesteryl methacrylate and methyl methacrylate copolymers having no flexible spacer.

Blumstein et al. ${ }^{11-14}$ prepared copolymers of cholesteryl methacrylate (ChMA) and methyl methacrylate (MMA) having no flexible spacer and found a sharp peak corresponding to a periodicity of $35.5 \mathrm{~A}$ in the small-angle $\mathrm{X}$ ray scattering (SAXS) of the solid copolymers. But they did not examine whether the copolymer behaves as a thermotropic liquid crys- talline polymer or not.

One of the authors, M.T. ${ }^{15}$ has also studied the effects of copolymer composition on the mesomorphic behavior of the ChMA-MMA copolymer and found the polymer to have a thermotropic nature, using polarized microscopy. But in these obsevations, the isotropic transition temperature was found to vary considerably with experimental conditions, not giving enough reproducible results. Under these circumstances, further attempt is made to examine the transitional behavior of these coploymers in more detail by thermal optical analysis (TOA). We here report an interesting thermotropic property of ChMA-MMA copolymers revealed by TOA, and a difference in the TOA curve due to the film casting method. The correlation of thermotropic nature with the stereoregularity of the ChMA-MMA copolymers is also discussed. 
K. SHôJı et al.

\section{EXPERIMENTAL}

\section{Materials}

All the solvents employed were distilled prior to use. Cholesterol was used without further purification. The ChMA was prepared by reaction of cholesterol with methacryloyl chloride in a solvent mixture of ether and toluene ( $1: 1$ by volume) at $80^{\circ} \mathrm{C}$ for $24 \mathrm{~h}$. The reaction mixture was then poured into methanol and the precipitated product was isolated with a yield of $63 \%$. A white needle-like crystal $\left(\mathrm{mp} 107.5^{\circ} \mathrm{C}\right)$ was obtained by repeating precipitation three times.

IR spectra of ChMA and cholesterol were measured with a Nihon Bunko 403-G spectrophotometer, and their ${ }^{1} \mathrm{H}$ NMR and ${ }^{13} \mathrm{C}$ NMR spectra with a JEOL FT-100.

\section{Solution Polymerization}

The homopolymerization of ChMA and copolymerization of ChMA-MMA were carried out by the method of Blumstein et al. ${ }^{17}$ The polymerizations were carried out in a benzene solution (total monomer concentration: $0.1 \mathrm{~mol}^{-1}$ ) at $60^{\circ} \mathrm{C}$ for $24 \mathrm{~h}$, using azobisisobutyronitrile (AIBN) as the initiator (0.01 moll $\left.1^{-1}\right)$. The copolymers were precipitated from the benzene solution into methanol and the remaining monomer was completely removed by ether extraction. The products were sufficiently dried at room temperature under vacuum.

The composition of the copolymers was determined from the ${ }^{1} \mathrm{H}$ NMR spectra.

\section{Molecular Weight}

Measurements of the number-average molecular weight $\left(M_{n}\right)$ of the copolymers was made by gel-permeation chromatography with an apparatus of Waters Associates GPC200, under the following conditions: solvent, tetrahydrofuran (THF); polymer concentration, 0.02 or $0.025 \%$; temperature, $40^{\circ} \mathrm{C}$ or $60^{\circ} \mathrm{C}$; column, polystyrene gel; standard materials, polystyrenes.
Thermal Optical Analysis (TOA)

TOA was carried out with a polarizing microscope using two types of films cast from the benzene solution (polymer concentration: $10 \mathrm{w} / \mathrm{v} \%$ ). One of the films was prepared by dropping the polymer solution onto a cover glass (open-type film). The other was prepared by interposing the polymer solution between two cover glasses (sandwich-type film). From both films the solvent was slowly evapolated at room temperature and then removed completely under vacuum for 7 days.

A TOA curve was obtained under a crosspolarized microscope (Union Optical Co., NUM-1) attached with a heating device in which the atmosphere was replaced with $\mathrm{N}_{2}$ gas flow. The heating rate was controlled at $2 \mathrm{~K} \mathrm{~min}^{-1}$ The polarized light transmittance through the film was measured by a handmade exposure meter equipped with a photo diode (Hamamatsu Telev. S1133) attached to the edge of a pair of eye lens, an OP amplifier and recorder (Nihon Denshi Kagaku: Unicorder U-228). The intensity of birefringence was determined in the scale where the $0 \%$ level corresponded to the intensity under crossed-nicols without the sample, and the $100 \%$ level to the intensity under parallelednicols.

\section{RESULTS AND DISCUSSION}

\section{Identification and Properties of Monomeric ChMA}

The monomeric ChMA was a white needlelike crystal with the melting point of $107.5^{\circ} \mathrm{C}$, which is the same as that reported in the literature. ${ }^{10,17}$ The absorption band assignments of ChMA and cholesterol are summarized in Table I.

Table II shows the assignments of the peaks appearing in the ${ }^{1} \mathrm{H}$ NMR spectra of ChMA, together with those of cholesterol and the copolymers. ${ }^{13} \mathrm{C}$ NMR measurement was carried out on ChMA and cholesterol. A peak originating from the carbon atom bonded to 
the hydroxyl group in cholesterol was found at $71.9 \mathrm{ppm}$, but did not appear completely in the spectra of monomer (Table III). Therefore,

Table I. IR assignments of cholesterol and monomeric ChMA

\begin{tabular}{lcc}
\hline & Cholesterol & ChMA \\
\hline C-OH & 3400 & - \\
C=O & - & 1713 \\
C-O-C & - & 1292 \\
C-O & 1050 & 1026 \\
& 1019 & 1010 \\
C=C & 1005 & - \\
C-H & 1667 & 1670 \\
& 840 & 837 \\
C=C & 806 & 792 \\
C-H & - & 1635 \\
\hline
\end{tabular}

cholesterol does not remain in the monomeric ChMA.

The monomer was soluble in benzene, chloroform, and ether but neither in methanol nor acetone.

Identification and Properties of the Copolymers Copolymers obtained had $M_{n}$ of 45,000 80,000 , depending upon the polymerization conditions as shown in Table IV.

The copolymer composition was determined by the ratio of the peak area appearing in ${ }^{1} \mathrm{H}$ NMR at $0.70 \mathrm{ppm}$, which was assigned to $18-$ $\mathrm{CH}_{3}$ in the cholesteryl group, and that at $3.66 \mathrm{ppm}$ assigned to methyl protons attached to oxygen atom in the ester linkage $\left(-\mathrm{O}-\mathrm{CH}_{3}\right)$ of the methyl methacrylate unit (Table IV).

All the copolymers were soluble in benzene,

Table II. ${ }^{1} \mathrm{H}$ NMR assignments of cholesterol, ChMA, and copolymer

\begin{tabular}{lccc}
\hline & Cholesterol $^{\mathrm{a}}$ & ChMA $^{\mathrm{a}}$ & Poly(ChMA-MMA) \\
\hline $18-\mathrm{CH}_{3}$ & 0.67 & 0.68 & 0.70 \\
$26,27-\mathrm{CH}_{3}$ & 0.87 & 0.79 & 0.86 \\
$21-\mathrm{CH}_{3}$ & 0.90 & 0.90 & 0.94 \\
$19-\mathrm{CH}_{3}$ & 1.00 & 1.02 & 1.22 \\
$-\mathrm{CH}_{2}-$ & 0.82 .4 & 0.82 .4 & - \\
$-\mathrm{O}_{-} \mathrm{CH}_{3}$ & - & - & 3.66 \\
$-\mathrm{CH}_{3}$ & - & 1.89 & - \\
$3-\mathrm{CH}$ & 3.49 & 4.55 & - \\
$6-\mathrm{CH}$ & 5.36 & 5.34 & - \\
$\mathrm{H}_{\mathrm{a}}$ & - & 5.45 & - \\
$\mathrm{H}_{\mathrm{b}}$ & - & 6.00 & - \\
\hline
\end{tabular}

a Measured at room temperature by $60 \mathrm{MHz}$ using $\mathrm{CCl}_{4}$ as a solvent.

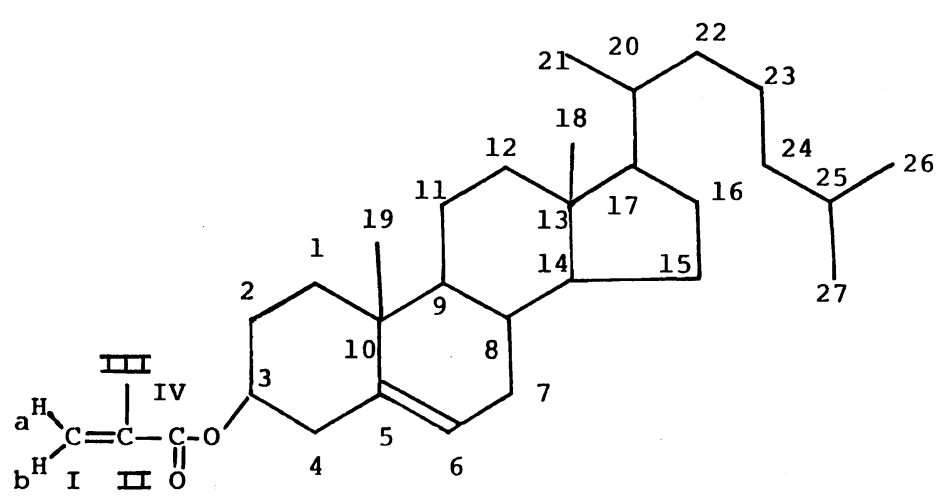


Table III. ${ }^{13} \mathrm{C}$ NMR assignments of cholesterol, MMA, and ChMA

\begin{tabular}{lccc}
\hline & Cholesterol $^{\mathrm{a}}$ & MMA $^{\mathrm{a}}$ & ChMA $^{\mathrm{a}}$ \\
\hline 5-C & 140.9 & - & 139.8 \\
6-C & 121.8 & - & 122.7 \\
$3-\mathrm{C}$ & 71.9 & - & 74.3 \\
18-C & 12.0 & - & 12.0 \\
IV-C & - & 167.9 & 166.9 \\
II-C & - & 135.9 & 136.9 \\
I-C & - & 124.5 & 124.9 \\
III-C & - & 17.6 & 18.4 \\
\hline \multirow{2}{*}{ a Obtained at room temperature using $\mathrm{CDCl}_{4}$ as a } \\
solvent.
\end{tabular}

Table IV. Solution copolymerization of ChMA with MMA

\begin{tabular}{|c|c|c|c|c|c|c|}
\hline \multirow{2}{*}{$\begin{array}{c}\text { Polymer } \\
\text { No. }\end{array}$} & \multicolumn{2}{|c|}{$\begin{array}{l}\text { Monomer feed } \\
\text { (mol fraction) }\end{array}$} & \multicolumn{2}{|c|}{$\begin{array}{l}\text { Composition } \\
\text { (mol fraction) }\end{array}$} & \multirow{2}{*}{$\frac{\text { Yield }}{\%}$} & \multirow{2}{*}{$M_{n}$} \\
\hline & ChMA & MMA & ChMA & MMA & & \\
\hline 1 & 0.90 & 0.10 & 0.92 & 0.08 & 88 & 80200 \\
\hline 2 & 0.80 & 0.20 & 0.85 & 0.15 & 90 & 72800 \\
\hline 3 & 0.70 & 0.30 & 0.72 & 0.28 & 86 & 45000 \\
\hline 4 & 0.50 & 0.50 & 0.52 & 0.48 & 90 & - \\
\hline 5 & 0.30 & 0.70 & 0.32 & 0.68 & 69 & - \\
\hline 6 & 0.10 & 0.90 & 0.09 & 0.91 & 84 & - \\
\hline
\end{tabular}

chloroform, carbon tetrachloride, and THF but neither in methanol nor ether.

\section{TOA}

Blumstein et al. ${ }^{11-14}$ reported that, at room temperature, the cast film shows a sharp peak of SAXS which might be caused by the smectic superstructure. In this study, however, both the open-type and sandwich-type cast films exhibited no anisotropy at room temperature.

When the sandwich type films containing more than $72 \mathrm{~mol} \%$ of ChMA were heated, they softened, and the transmitted polarized light was gradually intensified. For example, in the case of a copolymer (ChMA: $85 \mathrm{~mol}^{\circ} \%$ ), the light began to appear at about $166^{\circ} \mathrm{C}$, and the intensity increased with temperature as given in Figure 1. The maximum intensity was observed at $210^{\circ} \mathrm{C}$, above which

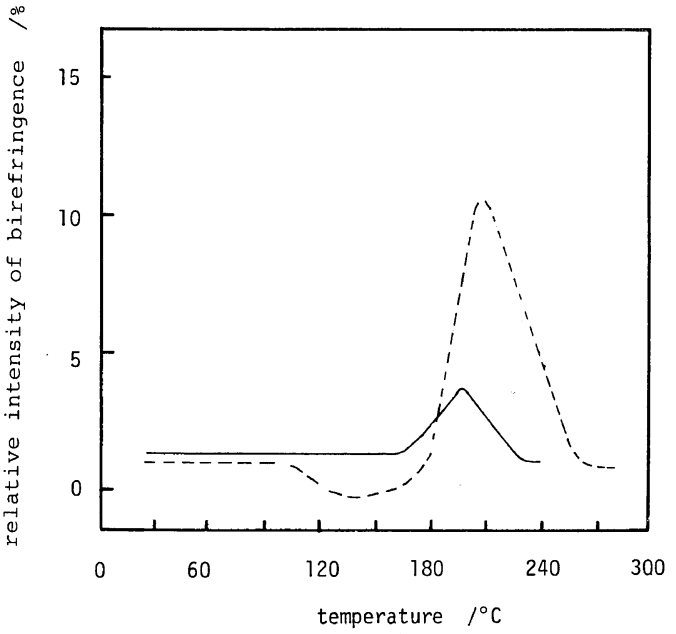

Figure 1. TOA curves for ChMA-MMA $(0.85: 0.15)$ copolymer film: ——, open type film; ----, sandwichtype film.

the light became weaker with increasing temperature and disappeared completely at $260^{\circ} \mathrm{C}$. The anisotropy was evident for the copolymers containing ChMA more than $72 \mathrm{~mol} \%$, but not for copolymers with less ChMA content. Owing to the gelation of casting solution on the cover glass, no TOA curve could be obtained for the copolymer (ChMA: $92 \mathrm{~mol} \%$ ).

The TOA curve of the open-type film of the copolymer (ChMA: $72 \mathrm{~mol}^{\circ} \%$ ) was in a reasonable agreement with that of the sandwich-type film. Thus the casting methods have no effect on the TOA curves for either sample.

But in the case of a copolymer (ChMA: $85 \mathrm{~mol}^{\circ} \%$ ), the isotropic temperature of the open-type film was found to be lower than that of the sandwich-type film.

The TOA curve of sandwich-type film of the ChMA homopolymer showed a single peak, whereas that of the open-type film showed two peaks. In the sandwich-type film, the copolymer was not fluid below the temperature corresponding the maximum intensity of birefringence, but highly fluid above the temperature. In the open-type film, the polymer did not flow in the lower temperature range where 


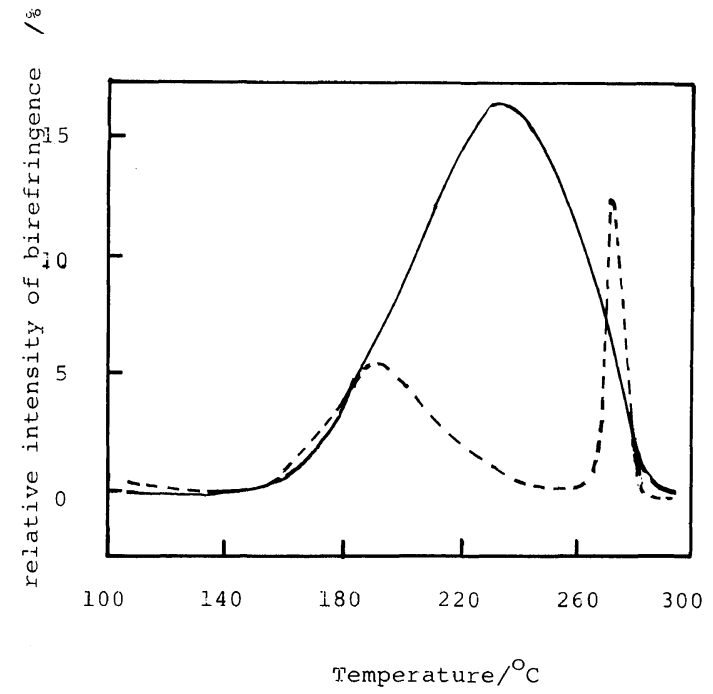

Figure 2. TOA curves of ChMA homopolymer obtained during first heating: —_, sandwich type; ----, open type.

the first peak was observed, but easily flowed in the higher temperature range of the second peak (Figure 2). It is well known that the arrangement of small molecule liquid crystal is strongly effected by the glass surface. But the mode of molecular arrangement is not established for liquid crystalline polymer at present. This may be closely related to the fluidity of molten copolymer or the interaction between polymer and glass surface.

There are remarkable differences between the two types of the films; the isotropic temperatures of copolymers with large fractions of ChMA are particularly effected by the casting method.

The observed transition temperatures are illustrated in Figure 3. as a phase diagram of the copolymers. With increasing ChMA fraction the isotropic temperature became higher. The anisotropic temperature range varied with the ChMA fraction.

The differential scanning calorimetry (DSC) was used to obtain the glass transition temperature $\left(T_{\mathrm{g}}\right)$, but no reproducible data were obtained. Accordingly, $T_{\mathrm{g}}$ data of Blumstein et $a l .{ }^{11}$ are referred to in Figure 3.

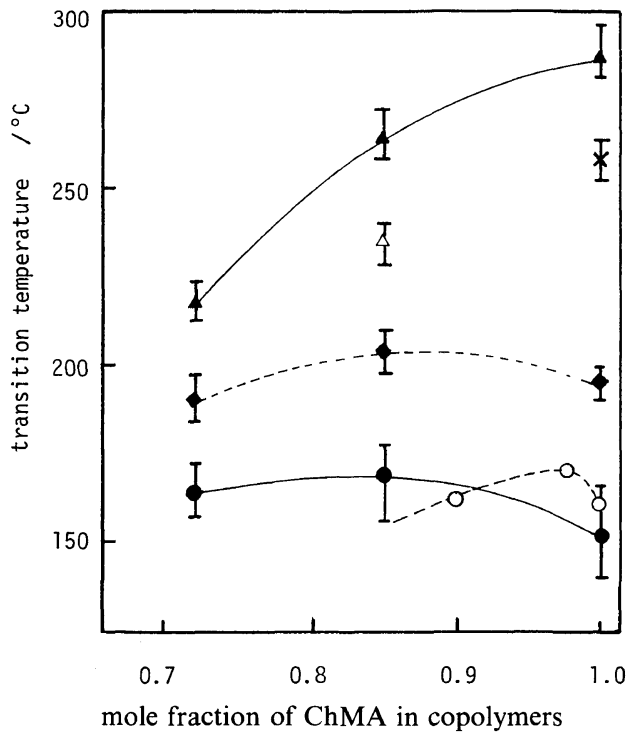

Figure 3. Phase diagram of ChMA-MMA copolymers obtained during first heating: $O, T_{\mathrm{g}}$ reported by Blumstein et al. ${ }^{11}$; , first appearance of birefringence; $\diamond$, maximum intensity of birefringence; $\Delta$, clearing temperature of open type film; $\times$, temperature at which birefringence vanished once (then appeared again abruptly); $\boldsymbol{\Delta}$, clearing temperature of sandwich-type film.

It is concluded that the temperature at which the anisotropy begins to appear is closely related to the $T_{\mathrm{g}}$. Furthermore, as the temperature decreases from anisotropic state even to as low as room temperature, the light transmittance did not change for either type of film.

The transition temperatures obtained by TOA were all reproducible throughout the experiments.

Wendorff et al. ${ }^{18}$ mentioned that the tendency to form smectic structures increases in the absence of spacer groups. Although red and green striped polarized light was observed in our observations, no characteristic texture of the smectic mesophase was observed.

Since it is well known that methacrylic polymers have generally rather low ceiling temperature, these compolymers would be liable to cause an unzippering reaction of the monomer at higher temperature. In this case, the optical-anisotropic nature of the copoly- 
mers might be caused by a complex mixture of polymer plasticized with the degradation products. If the anisotropy is caused by partial degradation of copolymer, an endothermic change would be observed by DSC. Studies using DSC with the copolymers showed that an exothermic change appeared during first heating step but none at the second steps. If this exothermic peak originated from the partial degradation reaction, the peak would be observed again during the second heating step. Although a slight degradation of the copolymer might be caused in the TOA apparatus, the optical-anisotropy is considered not to be due to the degradation but the intramolecular rearrangement of side groups. Further details of these subjects will be reported together with results in the following paper.

\section{Stereoregularity of the Copolymer}

Some reports ${ }^{19-23}$ have appeared on the effects of the stereoregularity of polymers on mesomorphic properties. It may be reasonable to expect that both liquid crystalline phase and mesomorphic temperature range are strongly influenced by the chemical structure of main chain and possibly its stereochemical configuration.

The stereoregularity of ChMA-MMA copolymers has been studied by one of the authors and his coworker, ${ }^{15}$ in which the relation between stereoregularity and the liquid crystalline nature has been discussed. Moreover, stereoregularity showed that triad tacticities were almost the same (I: $30, \mathrm{H}: 32$ and $\mathrm{S}: 40)$ in the ChMA mole fraction range from 0.4 to 0.6 , but that syndiotactic regularity increased abruptly with increasing ChMA content more than $72 \mathrm{~mol} \%$. In this study, the copolymers containing more than $72 \mathrm{~mol} \%$ of ChMA exhibited a clear thermotropic mesophase. This fact may be closely related to the syndiotactic structure of the copolymers.

Blumstein et al. ${ }^{20}$ pointed out that the smectic superstructure of the solid ChMA-MMA copolymer is not influenced by stereoregularity. Magagnini et al. ${ }^{22,23}$ reported that the smectic isotropic transition temperature of poly( $p$-biphenyl acrylate) increases with decreasing isotacticity. The results obtained in this study belong to the category of Takeda and Magagnini.

Moreover, Amerik et al. ${ }^{19}$ reported that the polymer of $p$-methacryloyloxy benzoic acid, obtained in the isotropic liquid phase, predominantly has the syndiotactic structure.

These data suggest that the packing of the bulky side groups favors a syndiotactic arrangement due to steric hindrance during propagation, and the syndiotactic arrangement is favorable to the stable mesomorphic state.

Acknowledgements. The authors should like to thank Professor Kazuyoshi Iimura and Professor Kenzi Tamaru of the Science University of Tokyo for their helpful comments and guidance.

\section{REFERENCES}

1. H. Kamogawa, J. Polym. Sci., B, 10, 7 (1972).

2. L. Strzelecki and L. Liebelt, Bull. Soc. Chim. Fr., 597 (1973).

3. H. Finkelmann, H. Ringsdorf, W. Soil, and J. H. Wendorf, Makromol. Chem., 179, 829 (1978).

4. V. P. Shibaev, N. A. Plate, and Ya. S. Freidzon, J. Polym. Sci. Polym. Chem. Ed., 17, 1655 (1979).

5. H. Finkelmann, H. Ringsdorf, W. Soil, and J. H. Wendorf, ACS Symp. Ser., 74, 22 (1978).

6. Gy. Hardy, K. Nyitrai, and F. Cser, IUPAC Internat. Symp., Macromol. Chem., Budapest, 1969, p 121.

7. W. J. Toth and A. W. Tobolsky, J. Polym. Sci., B, 8, 289 (1970).

8. A. C. DeVisser, J. Feyen, K. deGroot, and A. Banties, J. Polym. Sci., B, 10, 851 (1972).

9. Y. Tanaka, S. Kabaya, T. Shimura, A. Okada, Y. Kurihata, and Y. Sakakibara, J. Polym. Sci., B, 10, 261 (1972).

10. H. Saeki, K. Iimura, and M. Takeda, Polym. J., 3, 414 (1972).

11. E. C. Hsu, S. B. Clough, and A. Blumstein, J. Polym. Sci., B, 9, 545 (1977).

12. Y. Osada and A. Blumstein, J. Polym. Sci., B, 761 (1977). 


\section{TOA of Poly(ChMA-MMA)}

13. A. Blumstein, S. B. Clough, L. Patel, R. B. Blumstein, and E. C. Hsu, Macromolecules, 9, 243 (1976).

14. S. B. Clough, A. Blumstein, and E. C. Hsu, Macromolecules, 8, 123 (1976).

15. K. Iimura, T. Uchida, and M. Takeda, Rep. Prog. Polym. Phys., Jpn., 23, 275 (1980).

16. A. Blumstein, Y. Osada, S. B. Clough, E. C. Hsu, and R. Blumstein, ACS Symp. Ser., 74, 59 (1978).

17. A. Blumstein, Y. Osada, S. B. Clough, E. C. Hsu, and R. B. Blumstein, Polym. Prepr. Jpn., 18, 14 (1977).

18. J. H. Wendorff, H. Finkelmann, and H. Ringsdorf,
ACS Symp. Ser., 74, 19 (1978).

19. Yu. B. Amerik, I. I. Konstantinov, and B. A. Krentsel, J. Polym. Sci., 23, 231 (1968).

20. A. Blumstein, N. Kitagawa, and R. Blumstein, Mol. Cryst. Liq. Cryst., 12, 215 (1971).

21. M. Minezaki, H. Kumasaki, T. Nakaya, and M. Imoto, Polymer Preprint of 22th Annual Meeting of the Society of Polymer Science, 1973, G7, B02.

22. G. Ceccarelli, V. Frosini, P. L. Magagnini, and B. A. Newman, J. Polym. Sci., Polym. Lett. Ed., 13, 101 (1975).

23. V. Frosini, G. Levita, D. Lupinacci, and P. L. Magagnini, Mol. Cryst. Liq. Cryst., 66, 21 (1981). 